\title{
Effect of different artificial aging protocol- son fluorescence of resin composites
}

\author{
Elielson Nóbrega da Silva ${ }^{1}$, Ayla Macyelle de Oliveira Correia ${ }^{1}$, \\ Eduardo Bresciani ${ }^{1}$, Taciana Marco Ferraz Caneppele ${ }^{1}$
}

\begin{abstract}
${ }^{1}$ Department of Restorative Dentistry, São Paulo State University - UNESP- Institute of Science and Technology, CEP: 12245-000, São José dos Campos, São Paulo, Brasil.

e-mail: nobrega_elielson@hotmail.com, aylamacyelle@hotmail.com, eduardob@fosjc.unesp.br, taciana@fosjc.unesp.br
\end{abstract}

\begin{abstract}
This study evaluated the effect of different artificial aging on fluorescence of resin composites. Forty-five cylindrical specimens $(6 \mathrm{~mm}$ in diameter and $1 \mathrm{~mm}$ thick) were made of each resin composite: IPS Empress Direct, Filtek ${ }^{\mathrm{TM}}$ Z350 XT, and Durafill. A baseline measurement of fluorescence by the direct method using the fluorescence spectrophotometer RF-5301 PC was performed. After, resin specimens were divided into 3 groups according to artificial aging protocol to be submitted: (1) aging by mechanical brushing: 30,000 cycles were performed, with fluorescence measurements after 10,000, 20,000 and 30,000 cycles; (2) chemical aging by ethanol: the samples were immersed in ethanol for 15 days, with measurements after 5, 10 and 15 days of immersion; (3) light aging: resin specimens were subjected to UV radiation for 216h with fluorescence readings after $72,144,216 \mathrm{~h}$. Data were submitted to one-way repeated measures ANOVA and Tukey's test $(\alpha=0.05)$. Baseline fluorescence of the tested resins was ranked in this ascending order: Durafill $<$ Filtek Z350 XT < IPS Empress Direct. Simulated toothbrushing and ethanol immersion reduced fluorescence, except for Z350 XT. For light exposition, fluorescence was reduced after 100h for Empress Direct and Durafill, while a reduction after $100 \mathrm{~h}$ and $200 \mathrm{~h}$ was detected for Z350 XT. Artificial aging protocols influenced the fluorescence and that this phenomenon is material dependent. In general, the fluorescence is reduced with aging.
\end{abstract}

Keywords: composite resin, aging, fluorescence.

\section{INTRODUCTION}

The development and improvement of dental materials associated with the growing interest in cosmetic dentistry have significantly increased the use of composites [1,2]. Moreover, the development of these materials, especially as regards their optical properties (color, translucency, and fluorescence), became possible, by layering technique, to mimic characteristics of natural teeth [3].

Fluorescence, by definition, is the absorption of light by a substance and emission at the same time, in general in a longer wavelength [4]. Natural teeth emit a strong blue fluorescence under Ultra Violet light [5]. The fluorescence of the enamel is attributed mainly to its organic components, which correspond to $2 \%$ of its total composition [6] and is directly proportional to its thickness [7]. However, this optical property is mainly determined by dentin, due to the greater amount of amino acids, such as tryptophan, present in the collagen substrate [6]. The presence of ultraviolet light in the environment, such as in dance clubs, can change the appearance of teeth and restorations [8]. Therefore, to mimic the characteristics of natural teeth simulating their optical properties becomes even more challenging, because UV rays are emitted at different intensities, resulting in different patterns of the fluorescence of teeth and restorative materials.

The basic components of composite resins are not fluorescent, so, some studies $[9,10]$ have investigated possible ways to incorporate fluorescent agents in composites to provide fluorescent properties to this class of restorative material. To improve the aesthetics of the composite in all lighting conditions, rare earth oxides that are known fluorescent materials have been added to the glass filler particles as an additive fluorescent [9]. Furthermore, the fluorescent emission of an experimental resin was studied by adding a fluores- 
cent whitening agent comprising an aromatic compound in the polymer matrix [10]. However, there are still questions about the optical behavior of composites about the fluorescence intensity when compared between themselves and with the tooth structure, and particularly if this property can be affected by factors such as chemical agents, temperature, and exposition to light simulated by artificial aging.

Various aging protocols, such as thermal cycling, immersion in fluids such as water and ethanol, aging by light and mechanical (brushing) have been proposed to simulate the effects which the restorative materials are subjected to the oral environment. For mechanical aging with simulated brushing technique, different numbers of cycles are used [11-16]. Regarding the immersion in ethanol, LEPRINCE et al. [17] kept the samples immersed in ethanol for 24 hours for evaluation of mechanical properties. In another study [15] the resin composites were immersed for 10 days to assess degradation. MARGHALANI and WATTS [18] used the immersion for one month. SIDERIDOU et al. [19] assessed the degradation of resin composite after immersion in ethanol for 1 hour, seven days and 30 days. In studies using aging by light, there is no consensus on the radiation energy and time used exposure [20-23].

Few studies in the literature evaluated the fluorescence of resin composites, particularly regarding the influence of different artificial aging on this property [6]. Due to the importance of the fluorescence of restorations within the esthetic clinical parameters, it is important to assess how different aging methods can interfere with the composite's properties. Thus the objective of this study was assess the effect of different artificial aging on the fluorescence of three types of resin composite.

\section{MATERIAL AND METHODS}

\subsection{Specimen preparation}

The tested resin composites are listed in Table 1. A stainless steel matrix with $6 \mathrm{~mm}$ in diameter and $1 \mathrm{~mm}$ in thickness and was used to prepare 45 disc-shaped specimens of each material. The matrix was filled in with resin composite in one increment and covered by a Mylar strip. Then, a glass slide was positioned over the matrix and pressured for 10 s to produce a smooth and standardized surface. The resin composites were lightcured (Radii Cal curing light, SDI, Victoria, Australia; wavelength, 440-480 nm; intensity, $1200 \mathrm{~mW} / \mathrm{cm}^{2}$ ) for 40 s according to the manufacturer's instructions. The specimens were attached to a metal holder and polished with sequential (1200, 2400, and 4000 grit) aluminum oxide abrasive papers (FEPA-P, Struers, Ballerup, Denmark) in a polishing device (DP- 10, Panambra Industrial e Técnica SA, São Paulo, SP, Brazil) for 30s each.

Table 1: Materials details and manufacturers' specifications.

\begin{tabular}{|c|c|c|c|c|c|c|}
\hline Material & Manufacturer & Shade & Classification & Filler & $\begin{array}{c}\text { Filler (\% } \\
\text { vol.) }\end{array}$ & $\begin{array}{c}\text { Organicma- } \\
\text { trix }\end{array}$ \\
\hline $\begin{array}{c}\text { IPS Empress } \\
\text { Direct }\end{array}$ & $\begin{array}{l}\text { Ivoclar Vivadent, } \\
\text { Schaan, } \\
\text { Liechtenstein }\end{array}$ & EA2 & Nanohybrid & $\begin{array}{c}\text { Al-fluorosilicate glass Barium } \\
\text { glass fillers } 0.4 \mu \mathrm{m} \text {, prepolymer } \\
1-10 \mu \mathrm{m} \text {; spherical oxides } 150 \\
\mathrm{~nm}\end{array}$ & $52-59$ & $\begin{array}{l}\text { UDMA, } \\
\text { TCDD, Bis- } \\
\text { GMA }\end{array}$ \\
\hline $\begin{array}{l}\text { Filtek }^{\mathrm{TM}} \\
\text { Z350 XT }\end{array}$ & $\begin{array}{l}\text { 3M/ESPE, St. Paul, } \\
\text { MN, USA }\end{array}$ & $\mathrm{A} 2 \mathrm{E}$ & Nanofiller & $\begin{array}{l}\text { Aggregated } \mathrm{SiO} 2 / \mathrm{SrO} 2 \text { clusters } \\
(0.8-1.4 \mu \mathrm{m}) \text { e non- } \\
\text { agglomerated } \mathrm{SiO} 2(20 \mathrm{~nm})\end{array}$ & 59.5 & $\begin{array}{l}\text { Bis-GMA, } \\
\text { Bis-EMA, } \\
\text { UDMA, } \\
\text { TEGDMA }\end{array}$ \\
\hline Durafill & $\begin{array}{l}\text { HeraeusKulzerG- } \\
\text { mbH, Germany }\end{array}$ & $\mathrm{A} 2$ & Microfiller & $\begin{array}{c}\mathrm{SiO} 2(20-70 \mathrm{~nm}) \text {, prepoly- } \\
\text { mer<20nm. } \mathrm{SiO} 2 \text { in prepolymer }\end{array}$ & 66 & $\begin{array}{l}\text { Bis-GMA, } \\
\text { UDMA, } \\
\text { TEGDMA }\end{array}$ \\
\hline
\end{tabular}

\subsection{Fluorescence analysis}

Fluorescence measurements were performed with the RF-5301 PC spectrofluorophotometer (Shimadzu Corp., Kyoto, Japan) with excitation wavelength at $365 \mathrm{~nm}$. The samples were adapted in the equipment through solid sample holder. The emission spectrum (400 to $600 \mathrm{~nm}$ ) was obtained, and the value of emission peak in Fluorescence Units (F.U.) and wavelength were recorded using the "peak pick" tool of specific software (RFPC - Shimadzu Corp., Kyoto, Japan). It was chosen the excitation wavelength of $365 \mathrm{~nm}$ due to the fact it is in the ultraviolet spectrum and dentin exhibits a high fluorescence under this excitation [5]. 


\subsection{Artificial aging}

\subsubsection{Simulated toothbrushing}

The specimens were submitted to a simulated toothbrushing $\{30,000$ strokes/200 g, (Oral B 30, Procter \& Gamble, Brazil) + toothpaste slurry in a proportion of $1: 1$ by weight $[6 \mathrm{~g}$ of Colgate total 12 (ColgatePalmolive, São Paulo, Brazil) and $6 \mathrm{ml}$ of distilled water]\} in a brushing machine (MEV2, Odeme Biotechnology, Joaçaba, SC, Brazil). After each 10,000 strokes, fluorescence was assessed.

\subsubsection{Ethanol immersion}

The specimens were immersed and stored in $1 \mathrm{ml}$ of $75 \%$ ethanol/water at $37 \pm 1^{\circ} \mathrm{C}$ in individual glass vials for 15 days. After each five days, the ethanol solution was renewed, and the fluorescence of specimens was assessed.

\subsubsection{Light exposition}

The specimens were artificially aged in a weathering machine (SUNTEST CPS+ - Atlas Material Testing Technology $\mathrm{GmbH}$, Linsengericht, Hesse, Germany). The temperature was adjusted to $37 \pm 5^{\circ} \mathrm{C}$ and the irradiance to $765 \mathrm{~W} / \mathrm{m}^{2}$ to simulate an exposition of $160 \mathrm{Klux}$, corresponding to bright daylight, for $216 \mathrm{~h}$. During the artificial aging, samples were immersed in artificial saliva at $37 \pm 1^{\circ} \mathrm{C}$. After each $72 \mathrm{~h}$ of aging, fluorescence was assessed.

\subsection{Statistical analysis}

Data were submitted to repeated-measures ANOVA and Tukey's test $(\alpha=0.05)$ for each type of artificial aging.

\section{RESULTS}

The overall changes in fluorescence after all artificial aging are shown in Figures 1, 2 and 3. The crossproduct resin composite versus number of cycles as well as the factors was statistically significant $(\mathrm{p}<0.05)$.

In general, the tested resins behaved differently according to the different types of aging. At Baseline, Filtek $^{\mathrm{TM}}$ Z350 XT presented the lowest fluorescence values, followed by Durafill and IPS Empress Direct.

For simulated toothbrushing, repeated-measures ANOVA showed differences in the fluorescence through time for all the tested resins $(\mathrm{p}<0.05)$. The brushing negatively influenced the fluorescence over time for Durafill. Empress Direct and Z350 XT presented a similar pattern of fluorescence compared of to baseline while under tooth brushing (Figure 1).

The repeated-measures ANOVA revealed differences in the fluorescence after immersion in ethanol for all tested resin composites $(\mathrm{p}<0.05)$. The Empress Direct resin presented a fluorescence reduction for 5 and 10 days, stabilizing after 10 days (Figure 2). The ethanol immersion did not interfere in the fluorescence of the Z350 XT resin. For the Durafill, the fluorescence decreased only at the first immersion time, with no further reduction $(5=10=15$ days $)$.

There were statistically significant differences in the fluorescence through time for all the tested resins after light exposition $(\mathrm{p}<0.05)$. The fluorescence decreased in $100 \mathrm{~h}$ of exposition and stabilized after $200 \mathrm{~h}$ for Empress Direct and Durafill resins. For 350 XT, the fluorescence reduction occurred only in $100 \mathrm{~h}$ and $200 \mathrm{~h}$ of exposition (Figure 3). Only after the light exposition, Z350 XT resin had fluorescence intensities statistically similar to aged Empress Direct. A similar finding was made for to aged Durafill and Z350 XT without aging. 


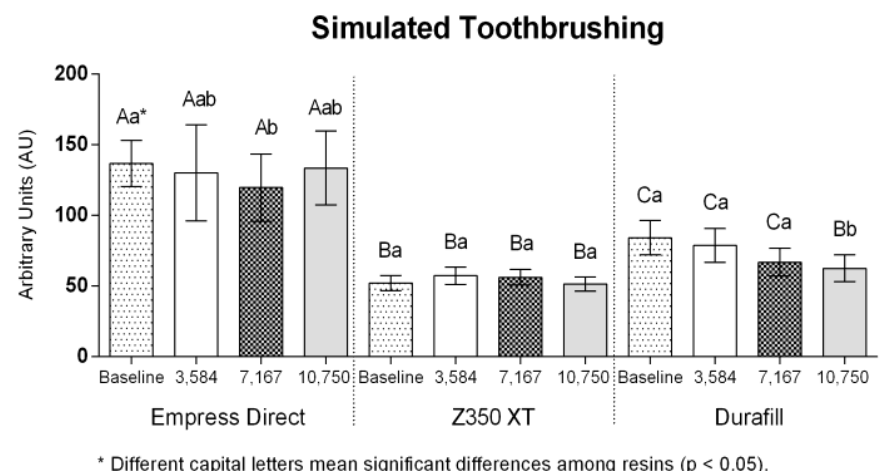

Different lowercase letters mean significant differences among number of cycles $(p<0.05)$.

Figure 1: Comparison of fluorescence about simulated toothbrushing.

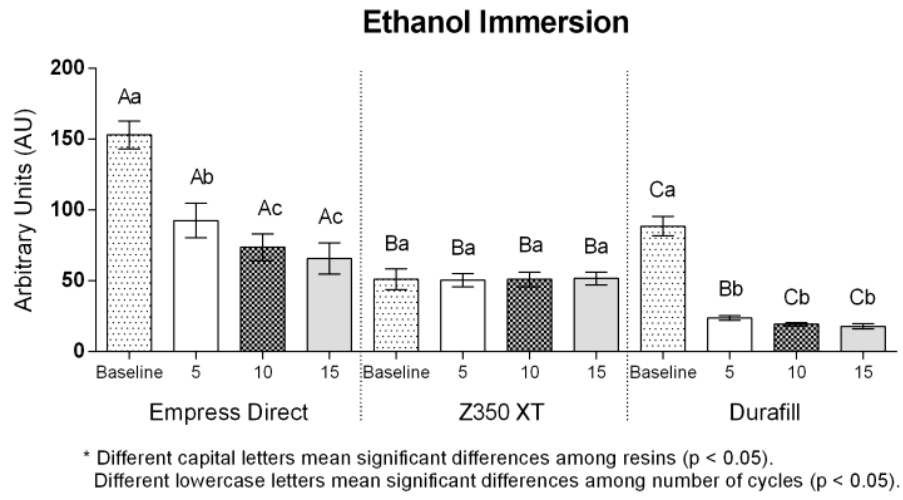

Figure 2: Comparison of fluorescence about ethanol immersion.

\section{Light Exposition}

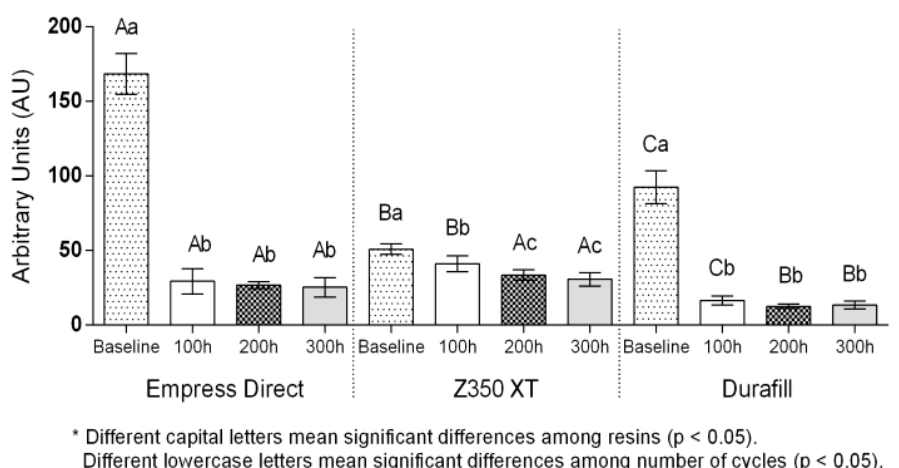

Figure 3: Comparison of fluorescence about light exposition.

\section{DISCUSSION}

Fluorescence in a restorative material tends to give a shiny effect and can be used to illuminate discolored teeth without adversely affecting the translucency [4]. It is, therefore, a clinically relevant factor, as it increases the liveliness of a restoration and minimizes tooth/restoration interface.

There is evidence that the fluorescence of the composites significantly changes after aging [6,24-26]. In this study, the artificial aging process caused significant alterations in fluorescence of all the tested resins. 
The most common patterns were a reduction at after artificial aging first cycle with subsequent stabilization or gradual reduction of fluorescence over cycles aging.

Simulated toothbrushing is a mechanical process able to wear the organic matrix and filler [27]. This wear is a dependent of the filler size and composition and can explain the reduction of fluorescence in resin composites [6]. In this study, the artificial aging decreased fluorescence only of Durafill after 10,750 cycles. Luminophores or mineral substances that are attached to the organic portion of dental composites could be broken by artificial aging. On the other hand, the performance for Empress Direct and Z350 XT resins might be related to being less prone to be rougher and worn, resulting in stabilization of fluorescence after artificial aging.

The chemical aging protocol used in this study should also be discussed and the results compared. Ethanol is used as a food-simulating liquid and can increase the solubility or plasticize the organic matrix of composites, simulating extremely food conditions [28]. In comparison to other fluids, alcohol can easily penetrate into the resin matrix of the composite [29], and results in elution of residual unreacted monomer, leading to defects on the surface as micro cracks and then macroscopic degradation of the organic matrix resin [29]. The resin matrix after undergoing degradation by ethanol exposes the particulate inorganic filler which can be released as macroscopic particles in the aging solution [30]. However, this degradation could be dependent of filler size [31], since differences in inorganic fillers and organic matrix influence the diffusion of aqueous solutions and ethanol. Then, it could result in different aging patterns and interfered the fluorescence values. That explains the present results, in which Empress Direct and Durafill presented the greatest fluorescence alterations after the second cycle (10 days) and first cycle (5 days), respectively. Filtek Z350 XT resin contains Bis-EMA, and this monomer is lesser soluble in ethanol than other monomers [32].

After the light exposition process, all the materials evaluated showed a significant reduction in fluorescence intensity over time. This effect also was verified by LEE et al. [33] and TAKAHASHI et al. [6] after exposing composites to light irradiation $\left(150 \mathrm{~kJ} / \mathrm{m}^{2}\right)$. It could be related to the degradation of organic complexes, found in resin composites, after aging [6]. The UV light has a photo-oxidative potential and induces the cleavage of single and double carbon bonds, responsible for the material deterioration.

Although the differences on the fluorescence alteration were detected among the tested resin composites, the artificial aging should not be compared with physiological aging [24]. Thus, these results provide useful information about the fluorescent properties of composite resins used for restorations. Nevertheless, more studies should be conducted to complement the present obtained results. This may contribute to the development of techniques for maintaining the fluorescence emission of the resin composite.

\section{CONCLUSION}

According to the methodology employed in this study, it could be concluded that:

1) the fluorescence intensity is significantly affected by the type of artificial aging and evaluation time and that this phenomenon is material dependent, with the Z350 XT resin presenting no fluorescence reduction after simulated toothbrushing and ethanol immersion.

2) differences in fluorescence intensity between the various brands of composite resin were observed regardless the aging protocols, with no defined pattern.

\section{ACKNOWLEDGMENTS}

This study was supported by Sao Paulo State Research Foundation - FAPESP (2013/21760-3).

\section{BIBLIOGRAPHY}

[1] CORREA, M. B., PERES, M. A., PERES, K. G., et al., "Amalgam or composite resin? Factors influencing the choice of restorative material”, Journal of Dentistry, v. 40, n. 9, pp. 703-10, Sep. 2012.

[2] FERRACANE, J. L., "Resin composite--state of the art", Dental materials : official publication of the Academy of Dental Materials, v. 27, n. 1, pp. 29-38, Jan. 2011.

[3] VANINI, L., "Light and color in anterior composite restorations", Practical periodontics and aesthetic dentistry: PPAD, v. 8, n. 7, pp. 673-82, quiz 84, Sep. 1996.

[4] MCLAREN, E. A., "Luminescent veneers", Journal of esthetic dentistry, v. 9, n. 1, pp. 3-12, 1997.

[5] SPITZER, D., BOSCH, J. J., "The total luminescence of bovine and human dental enamel", Calcified tissue research, n. 2, pp. 201-8, Apr. 1976. 
[6] TAKAHASHI, M. K., VIEIRA, S., RACHED, R. N., et al., "Fluorescence intensity of resin composites and dental tissues before and after accelerated aging: a comparative study", Operative dentistry, v. 33, n. 2, pp. 189-95, Mar-Apr. 2008.

[7] TAVARES, C. M., TAVARES, L. N., CORREIA, A. M. O., et al., "Effect of thickness on fluorescence of resin composites and dental substrates", Brazilian Dental Science, v. 19, n. 3, pp. 53-8, Jul-Sep. 2016.

[8] LEE, Y. K., LU, H., POWERS, J. M., "Fluorescence of layered resin composites", Journal of esthetic and restorative dentistry, v. 17, n. 2, pp. 93-100, Mar. 2005.

[9] UO, M., OKAMOTO, M., WATARI, F., et al., "Rare earth oxide-containing fluorescent glass filler for composite resin”, Dental materials journal, n. 24, v. 1, pp. 49-52, Mar. 2005.

[10] PARK, M. Y., LEE, Y. K., LIM, B. S., "Influence of fluorescent whitening agent on the fluorescent emission of resin composites", Dental materials : official publication of the Academy of Dental Materials, $\mathrm{v}$. 23, n. 6, pp. 731-5, Jun. 2007.

[11] JIN, J., TAKAHASHI, R., HICKEL, R., et al., "Surface properties of universal and flowable nanohybrid composites after simulated tooth brushing", American journal of dentistry, v. 27, n. 3, pp. 149-54, Jun. 2014.

[12] MONTEIRO, B., SPOHR, A. M., "Surface Roughness of Composite Resins after Simulated Toothbrushing with Different Dentifrices”, Journal of international oral health, v. 7, n. 7, pp. 1-5, Jul. 2015.

[13] ISHIKIRIAMA, S. K., OLIVEIRA, G. U., MAENOSONO, R. M., et al., "Wear and surface roughness of silorane composites after $\mathrm{pH}$ cycling and toothbrushing abrasion", American journal of dentistry, v. 27, n. 4, pp. 195-8, Aug. 2014.

[14] KAMONKHANTIKUL, K., ARKSORNNUKIT, M., TAKAHASHI, H., et al., "Polishing and toothbrushing alters the surface roughness and gloss of composite resins", Dental materials journal, v. 33, n. 5, pp. 599-606, 2014.

[15] BARUCCI-PFISTER, N., GOHRING, T. N., "Subjective and objective perceptions of specular gloss and surface roughness of esthetic resin composites before and after artificial aging", American journal of dentistry, v. 22, n. 2, pp 102-10, Apr. 2009.

[16] ARDU, S., BRAUT, V., UHAC, I., et al., "Influence of mechanical and chemical degradation on surface gloss of resin composite materials", American journal of dentistry, v. 22, n. 5, pp. 264-8, Oct. 2009.

[17] LEPRINCE, J. G., PALIN, W. M., VANACKER, J., et al., "Physico-mechanical characteristics of commercially available bulk-fill composites”, Journal of dentistry, v. 42, n. 8, pp. 993-1000, Aug. 2014.

[18] MARGHALANI, H. Y., WATTS, D. C., "Viscoelastic stability of resin-composites aged in foodsimulating solvents", Dental materials : official publication of the Academy of Dental Materials, v. 29, n. 9 , pp. 963-70, Sep. 2013.

[19] SIDERIDOU, I. D., VOUVOUDI, E. C., ADAMIDOU, E. A., "Dynamic mechanical thermal properties of the dental light-cured nanohybrid composite Kalore, GC: effect of various food/oral simulating liquids", Dental materials : official publication of the Academy of Dental Materials, v. 31, n. 2, pp. 154-61, Feb. 2015.

[20] CASTRO, D. T., LEPRI, C. P., VALENTE, M. L., et al., "Mechanical properties of silorane-based and methacrylate-based composite resins after artificial aging", General dentistry, v. 64, n. 2, pp. 56-9, Mar-Apr. 2016.

[21] CATELAN, A., SUZUKI, T. Y., BECKER, F. JR., et al., "Influence of surface sealing on color stability and roughness of composite submitted to ultraviolet-accelerated aging", Journal of investigative and clinical Dentistry, v. 8, n. 2, pp. 1-5, May. 2017.

[22] REIS, A. C., CASTRO, D. T., SCHIAVON, M. A., et al., "Microstructure and mechanical properties of composite resins subjected to accelerated artificial aging", Brazilian dental journal, v. 24, n. 6, pp. 599-604, Nov-Dec. 2013.

[23] GAINTANTZOPOULOU, M., KAKABOURA, A., LOUKIDIS, M., et al., "A study on colour stability of self-etching and etch-and-rinse adhesives”, Journal of dentistry, v. 37, n. 5, pp. 390-6, May. 2009.

[24] MATSUMOTO, H., KITAMURA, S., ARAKI, T., "Autofluorescence in human dentine in relation to age, tooth type and temperature measured by nanosecond time-resolved fluorescence microscopy", Archives of oral biology, v. 44, n. 4, pp. 309-18, Apr. 1999.

[25] LEE, Y. K., LU, H., POWERS, J. M., "Effect of surface sealant and staining on the fluorescence of resin composites", The Journal of prosthetic dentistry, n. 93, v. 3, pp. 260-6, Mar. 2005. 
[26] LIM, Y. K., LEE, Y. K., "Fluorescent emission of varied shades of resin composites", Dental materials : official publication of the Academy of Dental Materials, v. 23, n. 10, pp. 1262-8, Oct. 2007.

[27] OLIVEIRA, G. U., MONDELLI, R. F., CHARANTOLA RODRIGUES, M., et al., "Impact of filler size and distribution on roughness and wear of composite resin after simulated toothbrushing", Journal of applied oral science, v. 20, n. 5, pp. 510-6, Sep-Oct. 2012.

[28] MCKINNEY, J. E., WU, W., "Chemical softening and wear of dental composites", Journal of dental research, v. 64, n. 11, pp. 1326-31, Nov. 1985.

[29] BAUER, H., ILIE, N., "Effects of aging and irradiation time on the properties of a highly translucent resin-based composite", Dental materials journal, n. 32, v. 4, pp. 592-9, 2013.

[30] ZHOU, M., DRUMMOND, J. L., HANLEY, L., "Barium and strontium leaching from aged glass particle/resin matrix dental composites", Dental materials : official publication of the Academy of Dental Materials, v. 21, n. 2, pp. 145-55, Feb. 2005.

[31] D'ALPINO, P. H., SVIZERO NDA, R., BIM JUNIOR, O., et al., "Effects of age condition on the distribution and integrity of inorganic fillers in dental resin composites", Clinical oral investigations, v. 20, n. 5, pp. 1011-9, Jun. 2016.

[32] SIDERIDOU, I. D., KARABELA, M. M., "Sorption of water, ethanol or ethanol/water solutions by light-cured dental dimethacrylate resins", Dental materials : official publication of the Academy of Dental Materials, v. 27, n. 10, pp. 1003-10, Oct. 2011.

[33] LEE, Y. K., LU, H., POWERS, J. M., "Changes in opalescence and fluorescence properties of resin composites after accelerated aging", Dental materials : official publication of the Academy of Dental Materials, v. 22, n. 7, pp. 653-60, Jul. 2006. 